\title{
Investigating the efficacy of allograft cellular bone matrix for spinal fusion: a systematic review of the literature
}

\author{
Ryan R. Diaz, MD, Amey R. Savardekar, MD, MCh, Jared R. Brougham, MD, \\ Danielle Terrell, MD, MPH, and Anthony Sin, MD \\ Department of Neurosurgery, Louisiana State University Health Sciences Center, Shreveport, Louisiana
}

\begin{abstract}
OBJECTIVE The use of allograft cellular bone matrices (ACBMs) in spinal fusion has expanded rapidly over the last decade. Despite little objective data on its effectiveness, ACBM use has replaced the use of traditional autograft techniques, namely iliac crest bone graft (ICBG), in many centers.

METHODS In accordance with PRISMA (Preferred Reporting Items for Systematic Reviews and Meta-Analyses) guidelines, a systematic review was conducted of the PubMed, Cochrane Library, Scopus, and Web of Science databases of English-language articles over the time period from January 2001 to December 2020 to objectively assess the effectiveness of ACBMs, with an emphasis on the level of industry involvement in the current body of literature.

RESULTS Limited animal studies $(n=5)$ demonstrate the efficacy of ACBMs in spinal fusion, with either equivalent or increased rates of fusion compared to autograft. Clinical human studies utilizing ACBMs as bone graft expanders or bone graft substitutes ( $n=5$ for the cervical spine and $n=8$ for the lumbar spine) demonstrate the safety of ACBMs in spinal fusion, but fail to provide conclusive level I, II, or III evidence for its efficacy. Additionally, human studies are plagued with several limiting factors, such as small sample size, lack of prospective design, lack of randomization, absence of standardized assessment of fusion, and presence of industry support/relevant conflict of interest.
\end{abstract}

CONCLUSIONS There exist very few objective, unbiased human clinical studies demonstrating ACBM effectiveness or superiority in spinal fusion. Impartial, well-designed prospective studies are needed to offer evidence-based best practices to patients in this domain.

https://thejns.org/doi/abs/10.3171/2021.3.FOCUS2179

KEYWORDS allograft cellular bone matrix; cellular allograft; stem cell-based allograft; spine surgery; spine fusion; patient outcomes

$\mathrm{S}$ PINAL fusion surgeries for myriad indications have seen a gradual increase over the last 3 decades, with aggregate hospital costs for these procedures exceeding $\$ 10$ billion in 2015. ${ }^{1,2}$ The inability to achieve solid arthrodesis after performing spinal fusion frequently results in poor clinical outcomes, instrumentation failures, increased rates of revision surgery, and escalation of treatment costs. ${ }^{3}$ In addition to rigid spinal fixation with instrumentation, an essential component for solid arthrodesis is the bridging of bone surfaces, either with collected autograft or with commercial allograft products. The ideal graft material for spinal fusion must possess three critical physiological properties for achieving solid arthrodesis: osteogenesis, osteoinduction, and osteoconduction. ${ }^{4}$ The "gold standard" graft material is the autologous iliac crest bone graft (ICBG), possessing all three of the abovemen- tioned properties, which has been validated in numerous studies. ${ }^{1,5}$ However, the well-documented risks of donor site morbidity and long-term functional impairment have created notable interest in bone graft substitutes that can yield high fusion rates without the morbidity of bone harvesting. ${ }^{6-8}$ At this time, the only category of bone substitutes marketed as having the three critical physiological attributes is allograft cellular bone matrices (ACBMs), or CBMs. ${ }^{5}$ In the world of spine biologics, this entity of ACBMs was nonexistent a decade ago. Today, it has gained an approximately $10 \%$ share of the spine biologics market, which was estimated as $\$ 2.4$ billion in $2020 .^{9}$ As evidenced by this rapid market capture, there exists significant enthusiasm for ACBMs in spine fusion; however, the clinical efficacy of this group of novel bone graft expanders (BGEs) in comparison to the gold standard ICBG or to

ABBREVIATIONS ACBM = allograft CBM; $A C D F=$ anterior cervical discectomy and fusion; $A L I F=$ anterior lumbar interbody fusion; $B G E=$ bone graft expander; $B M P=$ bone morphogenetic protein; $\mathrm{CBM}=$ cellular bone matrix; $\mathrm{DBM}=$ demineralized bone matrix; $\mathrm{HCT} / \mathrm{Ps}=$ human cells, tissues, and cellular and tissue-based products; ICBG = iliac crest bone graft; MITLIF = minimally invasive TLIF; MSC = mesenchymal stem cell; PEEK = polyetheretherketone; PLF = posterolateral lumbar fusion; rhBMP = recombinant human BMP; TLIF = transforaminal lumbar interbody fusion; XLIF = extreme lateral interbody fusion.

SUBMITTED February 2, 2021. ACCEPTED March 22, 2021.

INCLUDE WHEN CITING DOI: 10.3171/2021.3.FOCUS2179. 
Diaz et al.

TABLE 1. Commonly used CBM products and their characteristics

\begin{tabular}{|c|c|c|c|c|}
\hline CBM Product & Associated Companies & Components & Cell Count & Cell Viability* \\
\hline ViviGen & $\begin{array}{l}\text { DePuy Synthes, } \\
\text { LifeNet Health, } \\
\text { Johnson \& Johnson }\end{array}$ & $\begin{array}{l}\text { Lineage committed bone cells (MSCs removed), cortico- } \\
\text { cancellous chips, \& demineralized bone }\end{array}$ & Not available & $96 \%$ \\
\hline Trinity Evolution & Orthofix, MTF Biologics & $\begin{array}{l}\text { Cancellous bone w/ viable OPCs \& MSCs w/in the matrix } \\
\text { \& demineralized cortical bone component }\end{array}$ & $\begin{array}{l}\geq 250,000 \text { cells } / \mathrm{cm}^{3}(\geq 50,000 \\
\text { cells/cm }{ }^{3} \text { are } \mathrm{MSCs} \& / \mathrm{or} \\
\text { OPCs) }\end{array}$ & Not available \\
\hline Trinity ELITE & Orthofix, MTF Biologics & $\begin{array}{l}\text { Cancellous bone, demineralized cortical fibers, viable } \\
\text { MSCs, OPCs, \& bone-forming cells }\end{array}$ & $\begin{array}{l}\geq 750,000 \text { cells } / \mathrm{cm}^{3}(\geq 250,000 \\
\text { cells } / \mathrm{cm}^{3} \text { are MSCs, OPCs, } \\
\quad \text { \& bone-forming cells })\end{array}$ & $\geq 70 \%$ \\
\hline Osteocel Plus & NuVasive & $\begin{array}{l}\text { Cancellous bone w/ viable OPCs, MSCs, osteoblasts, \& } \\
\text { other cells along osteogenic lineage combined w/ DBM }\end{array}$ & $>250,000$ cells $/ \mathrm{cm}^{3}$ & $>70 \%$ \\
\hline $\begin{array}{l}\text { VIA Graft, VIA } \\
\text { Form }\end{array}$ & Vivex Biologics & $\begin{array}{l}\text { Proprietary blend of microparticulate cortical, } \\
\text { cancellous, \& demineralized cortical allograft bone }\end{array}$ & $\geq 150,000$ viable cells $/ \mathrm{cm}^{3}$ & $>80 \%$ \\
\hline Fibercel & $\begin{array}{l}\text { Medtronic, Aziyo } \\
\text { Biologics }\end{array}$ & $\begin{array}{l}\text { Cancellous bone particles w/ preserved cells combined } \\
\text { w/ demineralized cortical fiber }\end{array}$ & $\begin{array}{l}\text { Average of } 650,000 \text { viable } \\
\text { cells } / \mathrm{cm}^{3}\end{array}$ & $100 \%$ \\
\hline Map3 & RTI Surgical & Cortical cancellous bone chips, DBM, \& MAPC class cells & $\geq 50,000$ viable cells $/ \mathrm{cm}^{3}$ & Not available \\
\hline $\mathrm{BIO}^{4}$ & Stryker & $\begin{array}{l}\text { Endogenous bone-forming cells including MSCs, OPCs, } \\
\& \text { osteoblasts as well as osteoinductive \& angiogenic } \\
\text { growth factors }\end{array}$ & $\geq 600,000 \mathrm{cells} / \mathrm{cm}^{3}$ & $\geq 70 \%$ \\
\hline $\begin{array}{l}\text { PrimaGen } \\
\text { Advanced, Cel- } \\
\text { lentra Advanced }\end{array}$ & Zimmer-Biomet & $\begin{array}{l}\text { Cancellous matrix, demineralized cortical bone, \& viable } \\
\text { cells found w/in the cancellous matrix }\end{array}$ & $\geq 750,000 \mathrm{cells} / \mathrm{cm}^{3}$ & $\geq 70 \%$ \\
\hline
\end{tabular}

MAPC = multipotent adult progenitor cell; OPC = osteoprogenitor cell.

All information was obtained from the manufacturer's website or e-brochure.

* After recommended thawing process.

other BGEs such as demineralized bone matrices (DBMs) remains elusive even 7-8 years after their FDA approval and continued use in clinical settings. ${ }^{9}$ This systematic review provides a snapshot of the existing literature on the level of evidence for efficacy of ACBMs in spinal fusion. Table 1 enumerates the commercially available ACBMs and their qualities.

\section{Methods}

A systematic review of the literature was conducted to analyze the current literature concerning ACBMs. Our primary goals were to 1) summarize the available literature (in vivo as well as in human clinical studies) on ACBMs in spine fusion and 2) objectively review evidence supporting the use of ACBMs in spinal fusion, specifically with respect to level of evidence and conflict of interest. A detailed protocol about the literature search, inclusion/exclusion criteria, and selection of studies was developed. We adhered to the PRISMA (Preferred Reporting Items for Systematic Reviews and Meta-Analyses) guidelines. ${ }^{10}$ The search strategy was designed around the PICOTS (population, intervention, comparison/control, outcome, and time) question format: is there evidence in the published literature (study design) demonstrating the efficacy of ACBMs as bone graft substitutes (intervention) in spinal fusion in human studies (or in vivo animal studies [population]) with respect to clinical or radiological outcomes (outcomes)? Two investigators (R.R.D. and A.R.S.) independently performed the literature search. To minimize selection bias, two reviewers (D.T. and J.R.B.) reviewed the articles separately and decided which of the final articles conformed to the inclusion criteria. In cases of dissent, a mutual consensus was reached after discussion with the senior author (A.S.).

\section{Literature Search Strategy}

A literature search was conducted of titles and abstracts from January 2001 to December 2020 in PubMed, the Cochrane Library database, Scopus, and Web of Science. A combination of keywords was used to build a search strategy. Only English-language articles were searched. Keywords used to build the search directory were ["cellular bone matrix" OR "viable bone matrix" OR "cellular allograft" OR "stem-cell based allograft" OR "allograft cellular bone matrix"] AND ["spine surgery" OR "spinal fusion" OR "spine fusion"] AND ["efficacy" OR "effectiveness"]. We included all human as well as animal studies that used ACBMs as a bone substitute or BGE for performing instrumented or noninstrumented (especially in animal studies) spinal fusion and documented the clinical and/or radiological outcomes of the fusion. Because of the scarcity of published material on ACBMs in spinal fusion, all available publications were included. Review articles or articles not reporting original data were excluded from our systematic review; however, they were used as resources for discussion. The search process is detailed in Fig. 1; more extensive details on the database searches are found in the Supplementary Material. 
Primary search with MeSH terms ["cellular bone matrix" OR "viable bone matrix" OR "cellular allograft" OR "stem-cell based allograft" OR "allograft cellular bone matrix"] AND ["spine surgery" OR "spinal fusion" OR "spine fusion"] AND [“efficacy" OR "effectiveness"]

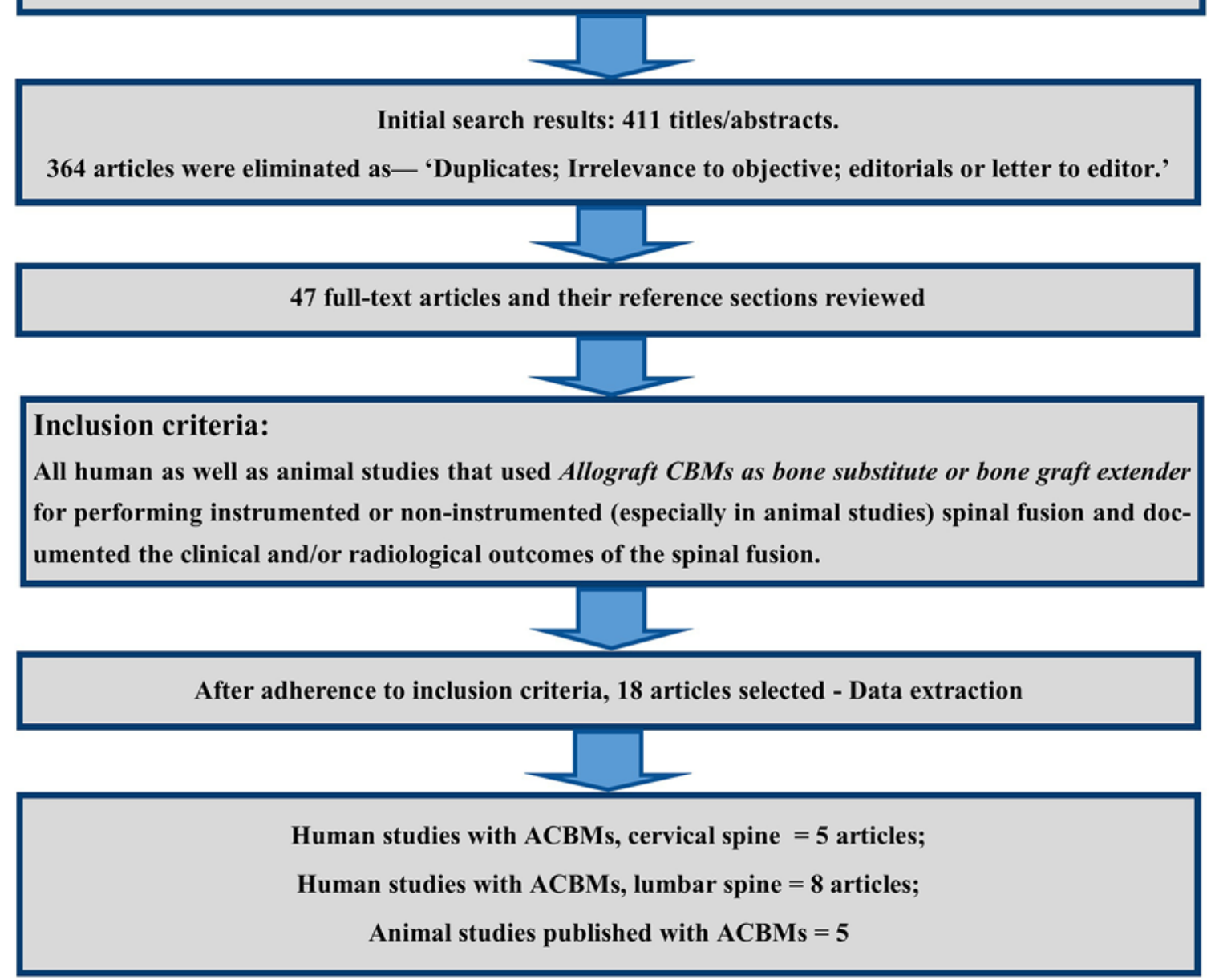

FIG. 1. The literature search strategy for the systematic review and process of selection of final articles is detailed as per PRISMA guidelines.

\section{Data Extraction}

The full texts of the selected articles were reviewed for the following data: information on study design (prospective, retrospective, matched-cohort), patients (age, sex, and number of patients), surgical indications (trauma or degenerative spine), surgical treatment (lumbar or cervical spine, number of levels, type of surgery performed), clinical outcomes (in terms of pain scores and disability scored), radiological outcomes (fusion rates as per criteria specified in the study), and presence or absence of industry support or presence of authors with relevant conflicts of interest. If further information was needed, authors were directly contacted.

\section{Results}

\section{PubMed Search and Characteristics of Selected Studies}

The initial search identified 411 publications, which were retrieved in abstract format. At the outset, we had planned strict adherence to the inclusion criteria, but the scarcity of literature pertaining to the effectiveness of ACBMs in spine surgery prompted us to include all available published research on this topic, including in vivo animal research. All human clinical studies and animal research in which ACBMs were used as bone substitutes or BGEs and where clinical and/or radiological outcome data were provided were included. The final 18 selected articles for the systematic review included 5 publications pertaining to animal research, ${ }^{11-15} 5$ publications pertaining to ACBM use in cervical spine surgery in human subjects, ${ }^{16-20}$ and 8 publications pertaining to ACBM use in lumbar spine surgery in human subjects. ${ }^{21-28}$ Tables 2 and 3 detail the study characteristics, patient profiles, and study outcomes for ACBM use in human clinical studies in cervical spine and lumbar spine surgery, respectively. 







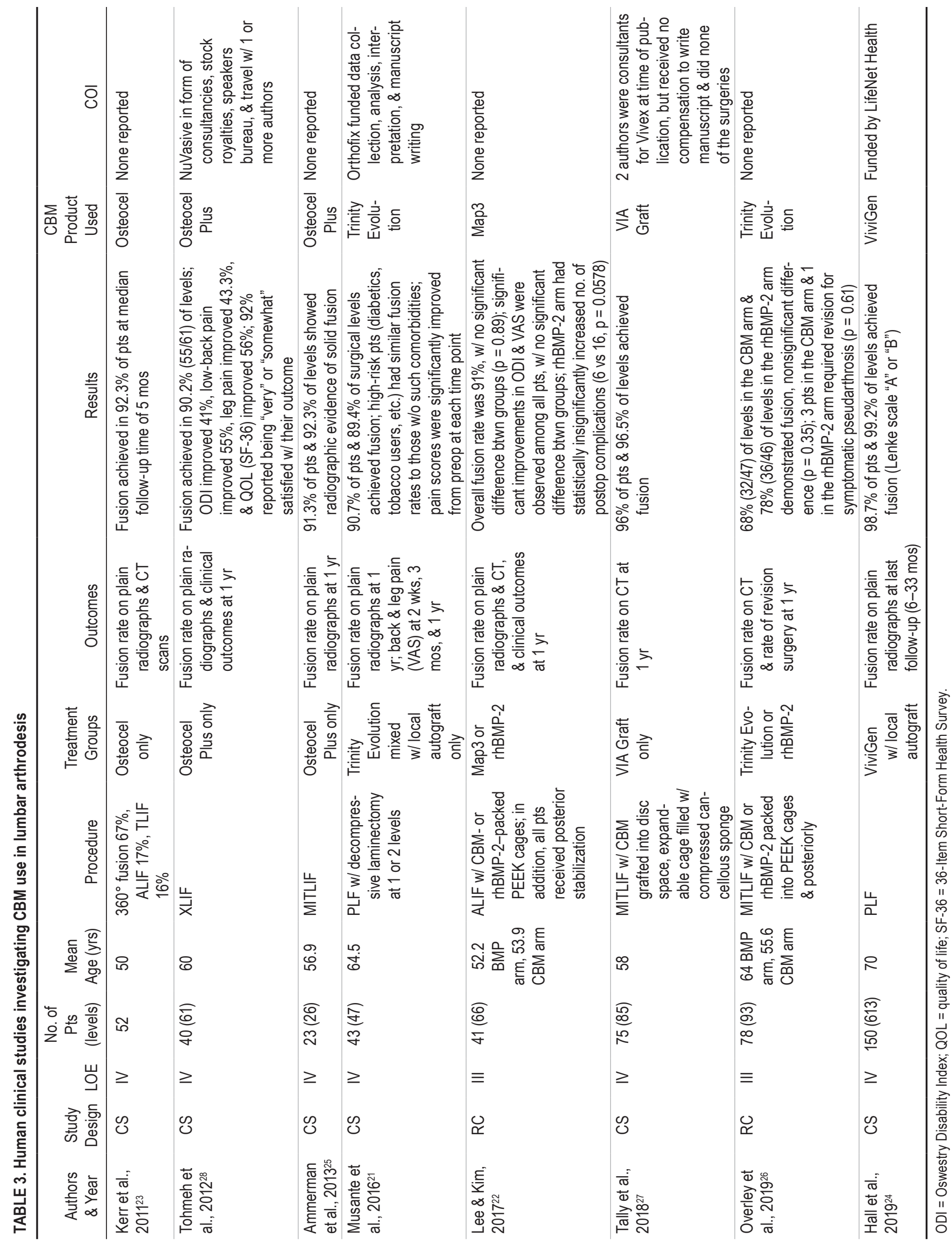




\section{Discussion}

\section{Scientific Rationale for ACBMs}

The goal of ACBMs is to target physiological bone formation in human injury. Dedicated laboratory and clinical research has resulted in the identification of the processes of osteoinduction, osteoconduction, and osteogenesis. ${ }^{29}$ Through mimicry of these intertwined natural processes, commercial products seek to provide an alternative to autograft with the added benefit of reducing morbidity and complications that have been associated with autograft harvesting. ${ }^{6,7,30}$ To better understand the ACBM products available to surgeons, one must understand these principles to help with the decision-making process when selecting among the myriad commercially available bone graft products.

Osteoinduction is the property of a material to promote attraction and differentiation of primitive cell lines into those involved with bone formation. Typically, mesenchymal stem cells (MSCs) are targeted as the precursor cell line and have been shown to differentiate into osteoprogenitor cells. ${ }^{31}$ To complete this differentiation process successfully, the microenvironment in which bone formation is to occur must be fostered. In 1965, the identification of this phenomenon was noted by Urist after implanting a DBM into muscular tissue resulting in bone formation..$^{32}$ The exact admixture of bone morphogenetic proteins (BMPs) has been studied and found to not be a static concentration of these various factors, in a single limited proprietary study from Biomet. ${ }^{33,34}$ This factor is an area of interest as well as a challenge to those looking to re-create the autogenic bone formation process using allogeneic materials.

Osteoconduction is the property of a material for bone to grow on its surface. Variables identified that influence osteoconductivity of a material involve its composition and surface morphology to work as a sufficient lattice over which cellular proliferation can occur, similar to the extracellular matrix that naturally occurs. The osteoconductive materials include, but are not limited to, acellular cortical or cancellous bone, calcium sulfate, calcium phosphate cements, ceramics, collagen, or synthetic polymers. ${ }^{35-38}$

Osteogenesis is the process of generation of new bone by delivered cells within ACBM. Allograft MSC lines are the targeted cell lines frequently in available products. These cells can be collected from donors, usually from bone marrow aspirate, and expanded in quantity in the laboratory to be implanted within an ACBM. These cell lines are then influenced via osteoinductive factors such as BMP to bone-forming cell lines, which helps to create an environment that serves to further propagate bone formation. ${ }^{39,40}$ MSCs are limited in their ability to trigger an immune reaction, which, in combination with their ability to differentiate to osteoblastic cell lines, makes them an ideal theoretical line to help establish osteogenesis. ${ }^{41} \mathrm{Al}-$ though the theory is robust, the data regarding proprietary cell lines are limited in part due to their regulation in the human cellular tissue product pathway. ${ }^{41}$

\section{Regulatory Processes Involved in Clearance for ACBMs}

In the US, the FDA, specifically the Center for Biolog- ics Evaluation and Research, is responsible for setting the regulation standards for ACBMs under the Public Health Service (PHS) Act. ${ }^{42,43}$ The FDA has a risk-based approach to the regulation of "human cells, tissues, and cellular and tissue-based products (HCT/Ps)" under which ACBMs are typically designated. Under the authority of Section 361 of the PHS Act, the FDA established regulations for all HCT/ Ps to prevent the transmission of communicable disease. The FDA has published three rules to broaden the scope of products subject to regulation and to include more comprehensive requirements to prevent the introduction, transmission, and spread of communicable disease. The first rule requires firms to register and list their HCT/Ps with the FDA. The second requires tissue establishments to evaluate donors, through screening and testing, to reduce the transmission of infectious diseases through tissue transplantation. The third rule requires approval through Title 21 of the Code of Federal Regulations Part 1271, 21 CFR 1271.10(a)(1) for minimal manipulation and 21 CFR 1271.10(a)(2) for homologous use. ${ }^{44}$ To obtain this designation, cellular products must meet the following criteria: 1) the HCT/P is minimally manipulated; 2) the HCT/P is intended for homologous use only, as reflected by the labeling, advertising, or other indications of the manufacturer's objective intent; 3) the manufacture of the HCT/P does not involve the combination of the cells or tissues with another article, except for water, crystalloids, or a sterilizing, preserving, or storage agent, provided that the addition of water, crystalloids, or the sterilizing, preserving, or storage agent does not raise new clinical safety concerns with respect to the HCT/P; and 4) either i) the HCT/P does not have a systemic effect and is not dependent upon the metabolic activity of living cells for its primary function, or ii) the HCT/P has a systemic effect or is dependent upon the metabolic activity of living cells for its primary function and a) is for autologous use, b) is for allogeneic use in a first-degree or second-degree blood relative, or c) is for reproductive use. If HCT/Ps do not meet these criteria, they can gain approval with an exception through 21 CFR 1271.15(b), which typically governs autologous HCT/Ps and is beyond the scope of this review. ${ }^{45}$ Once the ACBMs have been determined to meet the requirements in $21 \mathrm{CFR}$ 1271.10 , the company responsible must notify the FDA of the intent to market the product prior to it being placed into commercial use. There are no required studies or evaluations outside of these criteria prior to reaching the market. ${ }^{9}$

In contrast, some products, such as DBM BGEs, can be approved under the 501(k) section of the Food, Drug, and Cosmetic Act. Under this section of the act, a device can get FDA approval if it is found to have similar safety and effectiveness profiles to another marketed device, according to the following criteria: 1) it has the same intended use as the predicate, and 2) it has the same technological characteristics as the predicate; or 1) it has the same intended use as the predicate, and 2) it has different technological characteristics and does not raise different questions of safety and effectiveness, and 3) the information submitted to the FDA demonstrates that the device is as safe and effective as the legally marketed device. ${ }^{46}$ The recognized consensus standard of safety and efficacy of the FDA for spine modeling is the in vivo lumbar intertransverse fu- 
sion rabbit model. ${ }^{9,47}$ Lastly, if a product is deemed to not fit either the HCT/P pathway or the 501(k) pathway, it must undergo the most rigorous testing through the premarket approval (PMA) pathway. ${ }^{9}$ The FDA identifies this as "the most stringent" regulatory category for medical devices. The application for PMA requires "good science and scientific writing... If a PMA application lacks valid clinical information and scientific analysis on sound scientific reasoning, it could impact FDA's review and approval.'48 Thus, while ACBMs undergo vigorous screening to prevent the transmission of communicable diseases under the requirements of $21 \mathrm{CFR} 1271.10$, robust animal or clinical studies on the efficacy and cell contribution of ACBMs are scarce, unlike those for products with PMA.

\section{Current Evidence for ACBM Use via Animal Models Initial Animal Study}

In 2011, 2 years prior to any commercially available ACBM product, Goldschlager et al. were the first to show that implanting allogenic mesenchymal precursor cells (MPCs) may be a superior alternative to ICBG, the longstanding gold standard..$^{11}$ They did so using a sheep model for anterior cervical discectomy and fusion (ACDF) comparing polyetheretherketone (PEEK) cages packed with MPCs combined with hydroxyapatite and tricalcium phosphate (HA/TCP), HA/TCP alone, and ICBG. Evaluation of fusion on 3-month postoperative CT scans showed that MPC-treated animals had significantly more continuous bone bridging compared with ICBG- and HA/TCP-treated animals $(75 \%, 17 \%$, and $33 \%$, respectively). The density of new bone was also shown to be significantly higher within the MPC group (121\% higher than in HA/TCP and $128 \%$ higher than in ICBG), and macro motion at the fusion level was significantly reduced.

\section{Studies Showing Limited Efficacy of ACBM Products}

Bhamb et al. compared Osteocel Plus ACBM with 15 DBM, ceramic, and allograft products in a rat model of posterolateral lumbar fusion (PLF) and found no meaningful bone formation within the ACBM group, while the DBM group demonstrated excellent fusion overall. ${ }^{12}$ Similarly, Abedi et al. compared CBM containing DBM particles (Osteocel Pro), ACBM containing DBM fibers (ViviGen formable), and a 100\% DBM fiber product (OsteoStrand Plus) in a rat model of PLF..$^{15}$ The two products containing DBM fiber showed fusion rates of nearly $100 \%$ at 6 weeks, while the Osteocel Pro group demonstrated no fusion. Furthermore, cellular components of the ACBM products were tested both intact and devitalized using a standard drying protocol to cause cell lysis. Devitalized ACBM products demonstrated similar fusion rates to their vitalized counterparts, suggesting that the cellular component of CBM provided no additional benefit.

\section{Studies Comparing ACBM Products}

There are two well-designed studies comparing various commercially available ACBM products in the rat model for PLF, both of which were funded by the manufacturer and distributor of the Trinity line of ACBM products. In the first study, 6 commercially available ACBMs (Trin- ity ELITE, ViviGen, Cellentra, Osteocel $\mathrm{Pro} \mathrm{BIO}^{4}$, and Map3) were compared with ICBG from syngeneic rats. ${ }^{13}$ At 6 weeks, fusion rates by manual palpation were as follows: $5 / 15$ in the ICBG group, 11/15 in the Cellentra group, $8 / 15$ in the Trinity ELITE group, 2/15 in the ViviGen group, and 0/15 in the Osteocel Pro, $\mathrm{BIO}^{4}$, and Map3 groups. Cellentra and Trinity ELITE also showed significantly greater bone volume increases than other implants ( $73 \%$ and $65 \%$, respectively), seen on micro-CT as well as on histological analysis.

The second study compared Trinity Evolution, Trinity ELITE, Osteocel Plus, and syngeneic ICBG. ${ }^{14}$ By manual palpation over the grafted area, Trinity Evolution and Trinity ELITE allografts demonstrated the highest fusion rates, at $71 \%(10 / 14)$ and $77 \%$ (10/13), respectively. Osteocel Plus showed a significantly lower fusion rate than both Trinity products at $7 \%(1 / 14)$. Fusion was detected in $40 \%(6 / 15)$ of spines implanted with ICBG. On micro-CT and histopathologic analysis, both Trinity products demonstrated significantly higher bone fusion mass volumes than did Osteocel Plus or ICBG.

\section{Evidence for ACBM Use in Human Clinical Studies}

Tables 1 and 2 outline human clinical studies on ACBM use in both cervical and lumbar fusion, respectively. The vast majority of studies are low-evidence, uncontrolled case series. Additionally, variations in surgical technique, use of ACBM graft, patient characteristics and comorbidities, and definitions of bone fusion make results difficult to compare directly. Furthermore, many of these investigations are industry sponsored/funded or have authors with relevant conflicts of interest. A summary of relevant findings for each of these studies is detailed below.

\section{Cervical Spine}

Four case series and one retrospective cohort study have investigated ACBMs in cervical fusion. In 2016, McAnany et al. performed a retrospective cohort study comparing Osteocel ACBM to allograft in 114 matched patients (57 per arm) undergoing 1- to 2-level ACDF with an allograft spacer. ${ }^{18}$ In this study, $50.9 \%$ of patients underwent 1-level ACDF, while $49.1 \%$ underwent 2-level surgery. On 1-year follow-up CT, solid fusion was demonstrated in $87.7 \%$ of patients in the Osteocel group and $94.7 \%$ in the allograft control arm. This finding was not found to be statistically significant. Eastlack et al. investigated NuVasive's secondgeneration ACBM product, Osteocel Plus, in a noncontrolled prospective case series of 182 patients undergoing 1- to 2-level ACDF with a PEEK cage (249 levels treated). ${ }^{19}$ At the 2-year follow-up, 93\% of patients reported improvement in pain and functioning; $92 \%$ of patients undergoing 1-level surgery demonstrated solid fusion at 2 years, and the overall fusion rate was $87 \%$. MTF Biologics' ACBM product, Trinity Evolution, has been studied in two uncontrolled ACDF case series. In 1-level ACDF, the fusion rate was reported to be $78.6 \%$ at 6 months and $93.5 \%$ at 12 months $(\mathrm{n}=31) .{ }^{17}$ In 2-level ACDF, the fusion rate was reported to be $65.7 \%$ at 6 months and $89.4 \%$ at 12 months (n $=40) .{ }^{16}$ Significant clinical improvement in pain and function was reported at both time points in these studies. Divi and Mikhael investigated DePuy Synthes' ViviGen in 21 
TABLE 4. Cost analysis of bone graft products available at our institute as of January 2021

\begin{tabular}{|c|c|c|c|c|}
\hline Product & $\begin{array}{l}\text { Distributing } \\
\text { Company }\end{array}$ & $\begin{array}{l}\text { True Cost of Product } \\
\text { Available in Hospital }\end{array}$ & $\begin{array}{l}\text { Cost of } \\
\text { Product }\end{array}$ & $\begin{array}{c}\text { Average Cost for Type } \\
\text { of Graft Substitute }\end{array}$ \\
\hline \multicolumn{5}{|l|}{ Cancellous bone } \\
\hline Crushed cancellous bone & MTF Biologics & $\$ 294 / 15 \mathrm{~cm}^{3}$ & $\$ 20 / \mathrm{cm}^{3}$ & \multirow{2}{*}{$\$ 17 / \mathrm{cm}^{3}$} \\
\hline Cancellous bone chips & MTF Biologics & $\$ 208 / 15 \mathrm{~cm}^{3}$ & $\$ 14 / \mathrm{cm}^{3}$ & \\
\hline \multicolumn{5}{|l|}{ Demineralized bone matrix } \\
\hline Progenix Plus & Medtronic & $\$ 201 / \mathrm{cm}^{3}$ & $\$ 201 / \mathrm{cm}^{3}$ & \multirow{3}{*}{$\$ 151 / \mathrm{cm}^{3}$} \\
\hline DBX DBM & MTF Biologics & $\$ 153 / \mathrm{cm}^{3}$ & $\$ 153 / \mathrm{cm}^{3}$ & \\
\hline Xemplifi Plus & Globus & $\$ 300 / 3 \mathrm{~cm}^{3}$ & $\$ 100 / \mathrm{cm}^{3}$ & \\
\hline \multicolumn{5}{|l|}{ Allograft cellular bone matrix } \\
\hline Trinity ELITE & MTF Biologics & $\$ 495 / \mathrm{cm}^{3}$ & $\$ 495 / \mathrm{cm}^{3}$ & \multirow{3}{*}{$\$ 525 / \mathrm{cm}^{3}$} \\
\hline ViviGen & DePuy Synthes & $\$ 530 / \mathrm{cm}^{3}$ & $\$ 530 / \mathrm{cm}^{3}$ & \\
\hline Fibercel & Medtronic & $\$ 550 / \mathrm{cm}^{3}$ & $\$ 550 / \mathrm{cm}^{3}$ & \\
\hline
\end{tabular}

patients in an uncontrolled study. ${ }^{20}$ Eight patients underwent 3- to 4-level ACDF, 3 underwent cervical corpectomy and fusion, and 10 underwent posterior cervical fusion. All patients were reported to display fusion and improved pain/function at 6 months.

\section{Lumbar Spine}

The highest level of evidence for use of ACBMs in lumbar arthrodesis comes in the form of two retrospective cohort studies (level III evidence). The first was performed by Lee and Kim in 2017 and compared recombinant human (rh)BMP-2 ( $=21)$ versus Map3 ACBM $(n=20)$ in 1 - to 3-level anterior lumbar interbody fusion (ALIF). ${ }^{22}$ Both groups obtained similar fusion rates (91\% overall) and improvement in pain and disability at the 1-year follow-up. The Map3 group suffered fewer postoperative complications (6 vs 16); however, this finding was not statistically significant. In 2019, Overley et al. retrospectively compared fusion rates between Trinity Evolution and rhBMP-2 in 78 patients undergoing minimally invasive transforaminal lumbar interbody fusion (MITLIF). ${ }^{26}$ Again, no difference in radiographic fusion was found between the two groups.

The remainder of the literature on the use of ACBMs for lumbar arthrodesis is found in the form of level IV uncontrolled case series. Musante et al. demonstrated a 12-month fusion rate of $90.7 \%$ in patients $(n=43)$ undergoing PLF with decompressive laminectomy at 1-2 levels with Trinity Evolution and local autograft. ${ }^{21}$ Statistically significant improvements in lower-extremity and back pain were also reported. Hall et al. achieved an unprecedented fusion rate of $98.7 \%$ using ViviGen with local autograft in 150 patients who underwent PLF with an average of 4.1 levels/patient. ${ }^{24}$ Using the VIA Graft in MITLIF, Tally et al. also reported an exceptionally high fusion rate of $96 \%$ at 12 months on CT $(n=75) .{ }^{27}$ A smaller series of patients $(n=23)$ undergoing MITLIF with the Osteocel Plus graft reported a lower fusion rate of $91.3 \%$ at 12 months on plain radiographs. ${ }^{25}$ In a review of 52 consecutive patients undergoing interbody lumbar fusions (circumferential fusion $67 \%$, ALIF $17 \%$, transforaminal lumbar interbody fusion [TLIF] 16\%) with the Osteocel ACBM, 92.3\% achieved solid fusion. ${ }^{23}$ Tohmeh et al. performed extreme lateral in- terbody fusion (XLIF) with Osteocel Plus in 40 patients with $90.2 \%$ fusion at 12 months. ${ }^{28}$

\section{ACBMs: The Economic Perspective}

An important consideration while incorporating novel practices or products into a surgical procedure is the associated cost factor. ${ }^{18}$ Currently, ACBMs are marketed and sold at a premium as compared to other bone graft substitutes (such as DBM or cancellous bone chips) on the market. ${ }^{40}$ To get a simplified estimate of the added costs that ACBMs confer to spinal fusion, we analyzed the costs of the various bone graft substitutes or expanders available at our institution as of January 2021. We compared cancellous bone versus various DBMs versus various ACBMs in terms of product cost per cubic centimeter. On average (across various manufacturers), cancellous bone products cost $\$ 17$ per $\mathrm{cm}^{3}$, DBM products cost $\$ 151$ per $\mathrm{cm}^{3}$, and ACBM products cost $\$ 525$ per $\mathrm{cm}^{3}$ (Table 4). Thus, ACBMs are being sold at a premium in comparison to other bone graft substitutes. These costs are related to stringent donor screening and testing, sterile extraction techniques, proprietary cell line expansion techniques, and cold-chain maintenance for product viability. We are not debating the cost validation for the ACBM products; the query raised is for further investigation of bone graft substitutes that cost significantly more but have not been shown to be superior in efficacy in any study with level I, II, or III evidence.

\section{Conclusions}

Allograft CBMs have been in use since 2013 and at present command approximately $17 \%$ of the multibilliondollar US spine biologics market. Our systematic review suggests that unbiased or non-industry-sponsored evidence for efficacy of the cellular component of ACBMs is lacking and that the primary activity of ACBMs may be related to the activity and formulation of the DBM within, not their cellular component. Considering that ACBMs present an added expense to the healthcare industry, it is surprising that their application in spinal fusion surgery is on the rise. Our review elucidates the continued need for 
an impartial evaluation of ACBM efficacy, economics, and industry influence with respect to spinal fusion.

\section{References}

1. Plantz MA, Hsu WK. Recent research advances in biologic bone graft materials for spine surgery. Curr Rev Musculoskelet Med. 2020;13(3):318-325.

2. Martin BI, Mirza SK, Spina N, et al. Trends in lumbar fusion procedure rates and associated hospital costs for degenerative spinal diseases in the United States, 2004 to 2015. Spine (Phila Pa 1976). 2019;44(5):369-376.

3. Hsieh PC, Buser Z, Skelly AC, et al. Allogenic stem cells in spinal fusion: a systematic review. Global Spine J. 2019;9(1) (suppl):22S-38S.

4. Anand N. Overview of biologics. Spine (Phila Pa 1976). 2016;41(suppl 7):S10.

5. Kadam A, Millhouse PW, Kepler CK, et al. Bone substitutes and expanders in spine surgery: a review of their fusion efficacies. Int J Spine Surg. 2016;10:33.

6. Silber JS, Anderson DG, Daffner SD, et al. Donor site morbidity after anterior iliac crest bone harvest for single-level anterior cervical discectomy and fusion. Spine (Phila Pa 1976). 2003;28(2):134-139.

7. Arrington ED, Smith WJ, Chambers HG, et al. Complications of iliac crest bone graft harvesting. Clin Orthop Relat Res. 1996;(329):300-309.

8. Dimitriou R, Mataliotakis GI, Angoules AG, et al. Complications following autologous bone graft harvesting from the iliac crest and using the RIA: a systematic review. Injury. 2011;42(suppl 2):S3-S15.

9. Abjornson C, Brecevich A, Callanan T, et al. ISASS recommendations and coverage criteria for bone graft substitutes used in spinal surgery. Int J Spine Surg. 2018;12(6):757-771.

10. Moher D, Liberati A, Tetzlaff J, Altman DG. Preferred reporting items for systematic reviews and meta-analyses: the PRISMA statement. BMJ. 2009;339:b2535.

11. Goldschlager T, Rosenfeld JV, Ghosh P, et al. Cervical interbody fusion is enhanced by allogeneic mesenchymal precursor cells in an ovine model. Spine (Phila Pa 1976). 2011; 36(8):615-623.

12. Bhamb N, Kanim LEA, Drapeau S, et al. Comparative efficacy of commonly available human bone graft substitutes as tested for posterolateral fusion in an athymic rat model. Int J Spine Surg. 2019;13(5):437-458.

13. Lin C, Zhang N, Waldorff EI, et al. Comparing cellular bone matrices for posterolateral spinal fusion in a rat model. JOR Spine. 2020;3(2):e1084.

14. Johnstone B, Zhang N, Waldorff EI, et al. A comparative evaluation of commercially available cell-based allografts in a rat spinal fusion model. Int J Spine Surg. 2020;14(2): 213-221.

15. Abedi A, Formanek B, Russell N, et al. Examination of the role of cells in commercially available cellular allografts in spine fusion: an in vivo animal study. J Bone Joint Surg Am. 2020;102(24):e135.

16. Peppers TA, Bullard DE, Vanichkachorn JS, et al. Prospective clinical and radiographic evaluation of an allogeneic bone matrix containing stem cells (Trinity Evolution ${ }^{\circledR}$ Viable Cellular Bone Matrix) in patients undergoing two-level anterior cervical discectomy and fusion. J Orthop Surg Res. 2017; 12(1):67.

17. Vanichkachorn J, Peppers T, Bullard D, et al. A prospective clinical and radiographic 12-month outcome study of patients undergoing single-level anterior cervical discectomy and fusion for symptomatic cervical degenerative disc disease utilizing a novel viable allogeneic, cancellous, bone matrix (trinity evolution $^{\mathrm{TM}}$ ) with a comparison to historical controls. Eur Spine J. 2016;25(7):2233-2238.
18. McAnany SJ, Ahn J, Elboghdady IM, et al. Mesenchymal stem cell allograft as a fusion adjunct in one- and two-level anterior cervical discectomy and fusion: a matched cohort analysis. Spine J. 2016;16(2):163-167.

19. Eastlack RK, Garfin SR, Brown CR, Meyer SC. Osteocel Plus cellular allograft in anterior cervical discectomy and fusion: evaluation of clinical and radiographic outcomes from a prospective multicenter study. Spine (Phila Pa 1976). 2014; 39(22):E1331-E1337.

20. Divi SN, Mikhael MM. Use of allogenic mesenchymal cellular bone matrix in anterior and posterior cervical spinal fusion: a case series of 21 patients. Asian Spine J. 2017;11(3): 454-462.

21. Musante DB, Firtha ME, Atkinson BL, et al. Clinical evaluation of an allogeneic bone matrix containing viable osteogenic cells in patients undergoing one- and two-level posterolateral lumbar arthrodesis with decompressive laminectomy. J Orthop Surg Res. 2016;11(1):63.

22. Lee DD, Kim JY. A comparison of radiographic and clinical outcomes of anterior lumbar interbody fusion performed with either a cellular bone allograft containing multipotent adult progenitor cells or recombinant human bone morphogenetic protein-2. J Orthop Surg Res. 2017;12(1):126.

23. Kerr EJ III, Jawahar A, Wooten T, et al. The use of osteoconductive stem-cells allograft in lumbar interbody fusion procedures: an alternative to recombinant human bone morphogenetic protein. J Surg Orthop Adv. 2011;20(3):193-197.

24. Hall JF, McLean JB, Jones SM, et al. Multilevel instrumented posterolateral lumbar spine fusion with an allogeneic cellular bone graft. J Orthop Surg Res. 2019;14(1):372.

25. Ammerman JM, Libricz J, Ammerman MD. The role of Osteocel Plus as a fusion substrate in minimally invasive instrumented transforaminal lumbar interbody fusion. Clin Neurol Neurosurg. 2013;115(7):991-994.

26. Overley SC, McAnany SJ, Anwar MA, et al. Predictive factors and rates of fusion in minimally invasive transforaminal lumbar interbody fusion utilizing rhBMP-2 or mesenchymal stem cells. Int J Spine Surg. 2019;13(1):46-52.

27. Tally WC, Temple HT, Subhawong TY, Ganey T. Transforaminal lumbar interbody fusion with viable allograft: 75 consecutive cases at 12-month follow-up. Int J Spine Surg. 2018;12(1):76-84.

28. Tohmeh AG, Watson B, Tohmeh M, Zielinski XJ. Allograft cellular bone matrix in extreme lateral interbody fusion: preliminary radiographic and clinical outcomes. ScientificWorldJournal. 2012;2012:263637.

29. Giannoudis PV, Dinopoulos H, Tsiridis E. Bone substitutes: an update. Injury. 2005;36(suppl 3):S20-S27.

30. Almaiman M, Al-Bargi HH, Manson P. Complication of anterior iliac bone graft harvesting in 372 adult patients from May 2006 to May 2011 and a literature review. Craniomaxillofac Trauma Reconstr. 2013;6(4):257-266.

31. Albrektsson T, Johansson C. Osteoinduction, osteoconduction and osseointegration. Eur Spine J. 2001;10(suppl 2):S96S101.

32. Urist MR. Bone morphogenetic protein: the molecularization of skeletal system development. J Bone Miner Res. 1997; 12(3):343-346.

33. Pietrzak WS, Perns SV, Keyes J, et al. Demineralized bone matrix graft: a scientific and clinical case study assessment. $J$ Foot Ankle Surg. 2005;44(5):345-353.

34. Pietrzak WS, Woodell-May J, McDonald N. Assay of bone morphogenetic protein-2, -4, and -7 in human demineralized bone matrix. J Craniofac Surg. 2006;17(1):84-90.

35. Namikawa T, Terai H, Suzuki E, et al. Experimental spinal fusion with recombinant human bone morphogenetic protein-2 delivered by a synthetic polymer and beta-tricalcium phosphate in a rabbit model. Spine (Phila Pa 1976). 2005; 30(15):1717-1722. 
36. Fujibayashi S, Shikata J, Tanaka C, et al. Lumbar posterolateral fusion with biphasic calcium phosphate ceramic. J Spinal Disord. 2001;14(3):214-221.

37. Nickoli MS, Hsu WK. Ceramic-based bone grafts as a bone grafts extender for lumbar spine arthrodesis: a systematic review. Global Spine J. 2014;4(3):211-216.

38. Spiro RC, Thompson AY, Poser JW. Spinal fusion with recombinant human growth and differentiation factor-5 combined with a mineralized collagen matrix. Anat Rec. 2001; 263(4):388-395.

39. Nguyen LH, Duenas V, Chen MY, Jandial R. Progenitor cells: role and usage in bone tissue engineering approaches for spinal fusion. Adv Exp Med Biol. 2012;760:188-210.

40. Skovrlj B, Guzman JZ, Al Maaieh M, et al. Cellular bone matrices: viable stem cell-containing bone graft substitutes. Spine J. 2014;14(11):2763-2772.

41. Smith KA, Russo GS, Vaccaro AR, Arnold PM. Scientific, clinical, regulatory, and economic aspects of choosing bone graft/biological options in spine surgery. Neurosurgery. 2019; 84(4):827-835.

42. Food and Drug Administration. Code of Federal Regulations Title 21. Accessed April 16, 2021. https://www.accessdata. fda.gov/scripts/cdrh/cfdocs/cfcfr/cfrsearch.cfm?fr $=1271.10$

43. Food and Drug Administration. Center for Biologics Evaluation and Research (CBER). Accessed April 16, 2021. https: //www.fda.gov/about-fda/fda-organization/center-biologicsevaluation-and-research-cber

44. Food and Drug Administration. Regulatory Considerations for Human Cells, Tissues, and Cellular and Tissue Based Products: Minimal Manipulation and Homologous Use. Accessed April 16, 2021. https://www.fda.gov/media/109176/ download

45. Food and Drug Administration. Same Surgical Procedure Exception Under 21 CFR 1271.15(b): Questions and Answers Regarding the Scope of the Exception. Accessed April 16, 2021. https://www.fda.gov/media/89920/download

46. Food and Drug Administration. Premarket Notification 501(k). Accessed April 16, 2021. https://www.fda.gov/ medical-devices/premarket-submissions/premarketnotification-510k
47. Food and Drug Administration. Recognized Consensus Standards. Standard Guide for in vivo Evaluation of Rabbit Lumbar Intertransverse Process Spinal Fusion Model. June 7, 2018. Accessed April 16, 2021. https://www.accessdata.fda. gov/scripts/cdrh/cfdocs/cfStandards/detail.cfm?standard identification_no $=36749$

48. Food and Drug Administration. Premarket Approval (PMA). Accessed April 16, 2021. https://www.fda.gov/medicaldevices/premarket-submissions/premarket-approval-pma

\section{Disclosures}

The authors report no conflict of interest concerning the materials or methods used in this study or the findings specified in this paper.

\section{Author Contributions}

Conception and design: Sin, Savardekar, Brougham. Acquisition of data: Diaz. Analysis and interpretation of data: Diaz, Savardekar, Brougham, Terrell. Drafting the article: Diaz, Savardekar, Brougham, Terrell. Critically revising the article: Savardekar, Brougham, Terrell. Reviewed submitted version of manuscript: all authors. Approved the final version of the manuscript on behalf of all authors: Sin. Study supervision: Sin.

\section{Supplemental Information}

Online-Only Content

Supplemental material is available online.

Supplementary Material. https://thejns.org/doi/suppl/10.3171/ 2021.3.FOCUS2179.

\section{Correspondence}

Anthony Sin: LSU Health Sciences Center, Shreveport, LA. asin@lsuhsc.edu. 